\title{
THE DETERMINANTS OF EMPLOYEE PERFORMANCE IN JORDANIAN ORGANIZATIONS
}

\author{
DOI: 10.17261/Pressacademia.2018.780 \\ JEFA- V.5-ISS.1-2018(2)-p.11-17
}

\section{Zuheir Mohamed Dahkoul}

Al-Qassim University, The Society Faculty Buraydah, Po Box 6666, Postal Code 51452, Al-Qassim, Saudi Arabia. zohairkamel1965@qu.edu.sa, ORCID: 0000-0002-7671-8364

\section{To cite this document}

Dahkoul, Zuheir Mohamed. (2018). The Determinants of Employee Performance in Jordanian Organizations. Journal of Economics, Finance and Accounting (JEFA), V.5, Iss.1, p.11-17

Permemant link to this document: http://doi.org/10.17261/Pressacademia.2018.780

Copyright: Published by PressAcademia and limited licenced re-use rights only.

\section{ABSTRACT}

Purpose - The study aims to explore the determinants of employees' performance in Jordanian industrial sector specifically exploring the impact of employees' satisfaction, management standards and trainings on employee's performance while exploring the mediating impact of employees' engagement.

Methodology - Thus, a sample of 100 administrative and executive managers is selected from industrial sector of Jordan through convenient sampling. Primary data is collected, distributing 2 questionnaires to each organization; one for the administrative manager and one for the executive manager individually. Quantitative data analysis technique is adopted while implementing structural equation modelling through AMOS.

Findings- The study found that employees satisfaction, management standards and trainings are significant factors for employees' performance; having significant impact on employee engagement that ultimately leads towards employees' performance. But the most significant among these three is the employee satisfaction.

Conclusion- Organizations should focus on employee satisfaction, management standards and trainings to enhance their engagement towards work, hence improving their performance.

Keywords: Employees Performance, Employees Satisfaction, Management Standards, Trainings, Employee Engagement JEL Codes: L61, J83, J89

\section{INTRODUCTION}

Business sector is facing fierce competition across the globe thus organizations being aware about the importance of their human resource as a competitive advantage of organization. Employees create competitive advantage for organization through their performance thus organizations are mostly busy in finding out ways to attain highest possible levels of employees' performance (Liao and Chang, 2004). Managers are aimed at achieving corporate goals through enhanced employee performance in an effective and efficient way. Employees' performance may be enhanced through focusing on the factors that significantly influence their performance like their satisfaction (Harter, Schmidt and Hayes, 2002), management standards (Mackay et al, 2004) as well as trainings Liao and Chang, 2004). Due to fierce competition, organizations also try to attract others' best performing employees so that they may capture the competitive advantage in the market thus it has also become crucial for the organizations to retain their existing employees (Ellinger, Ellinger and Keller, 2003). Because organizations spend their resources to bring out the best from their employees like through trainings and developments etc. thus the trained employees are an asset for the organization and no organization wants to give their assets to anyone else. Such assets retain with the organization unless they are satisfied from their jobs (Gitongu, Kingi and Uzel, 2016). Thus, organizations are required to focus on such factors like employees' satisfaction, their trainings etc. to have an enhanced performance from them (Gruman and Saks, 2011). Moreover, the management standards to achieve their goals are also among the factors that are required to be analysed through their role in employees' performance (Mackay et al, 2004).

Thus, organizations are required to focus on the factors that contribute well in enhancing employees' performance because employees' performance has a direct link with the goal attainment of the organization. Employees' performance indicates 
their efficiency as well as their productivity leading towards organizational goal achievement through their positive contribution as employees' performance will ultimately result in the overall performance of the organization (Markos and Sridevi, 2010). Thus, organizations have realized the importance of enhanced employees' performance as organizations' goals cannot be achieved unless employees' performance is up to the marks (Anitha, 2014). They are required to focus on the factors that contribute in enhancing employees' performance.

Current research aimed at finding out the impact of such factors on employees' performance through their engagement towards work. Relationships among variables is analysed through structural equation modelling using AMOS because structural equation modelling best explains the relationship among independent and dependant variables in the presence of mediating variable.

\section{LITERATURE REVIEW}

The fierce competition in the business market, emerged due to globalisation, has forced organizations to create a competitive advantage for their survival or to move away from the market. thus, due to such emerging competition the importance of human resource has also been emerged as employees are the important source of competitive advantage (Rich, Lepine and Crawford, 2010). Organizations can enjoy the benefits of such competitive advantage if employees are performing up to the required levels i.e. contributing positively in the organizational growth and goal attainment (Liao and Chang, 2004). Thus, organizations are required to focus on the factors that may contribute positively in enhancing employees' performance to develop and retain the competitive advantage for them.

\subsection{Employee Performance}

Performance incorporates the resulting outcomes of the performed actions of employees based on their expertise and skills. In organizational settings, employees' performance is the accumulates result of the skills, efforts and abilities of all the employees contributed in organizational improved productivity leading towards its goal achievement. Improved organizational performance indicates the efforts towards goal achievement while requiring more efforts in terms of improved employee performance (Ellinger et al, 2003).

Employee performance is among the critical factors that contribute significantly in organizational success. Learning organizations play important role in enhancing employee performance through providing trainings and developments for their employees (Gitongu et al, 2016). Moreover, management standards to evaluate employee performance also play critical role in improving employee performance as they provide the picture of actual performance and its alignment with the benchmarks. If discrepancies found, then these standards help bringing the outputs again towards their required levels (Mackay et al, 2004). Employees performance also depends on their internal satisfaction towards their job. If employees are satisfied from their jobs as well as the organization than they are more keenly interested to perform well towards organizational goal achievement (Harter et al, 2002).

\subsection{Employees' Satisfaction}

Employees satisfaction indicates the happy and contented employees as they can fulfil their own desires and requirements through their jobs. Employee satisfaction leads towards their motivation and high morale to perform well enough to achieve the organizational goals (Harter et al, 2002). If organizational goals are aligned with the employees' personal goals than employees feel happier and contended towards their jobs and organizations. Thus, organizations are required to align the organizational goals in terms of employees' personal goal achievement as their satisfaction will lead them to enhance their contribution towards organizational goal achievement (Liao and Chang, 2004). Employee satisfaction can also be gained through treating them with respect, providing them with recognition in the organization, offering benefits beyond industry averages, offering employee perks and empowering them. These factors will contribute well in attaining employee satisfaction that will engage them more towards their work and ultimately improving their contribution towards goal attainment (Ellinger et al, 2003).

\subsection{Management Standards}

Management standards indicate traditional proven frameworks and methods based on comprehensive models and practice that are up-graded with the evolvement of industry, society and technology over time. Such standards are developed and retained by well-known industry bodies and facilitate organizations to attain success in repeatable manners by providing a consistent approach of evaluation. Management standards are a collection of conditions that illustrate good actions through step by step approach and facilitates the evaluation of current position based on pre-existing techniques, data and surveys (Mackay et al, 2004).

Management standards facilitate identifying the underlying risk factors for the organization and facilitate the employers to focus the basic causes and the ways to prevent such risks. Such standards also facilitate the organization to evaluate its goal achievement through evaluation of its employees' performance by making its comparison with the benchmarks (Gitongu et 
al, 2016). Management standards serve as a bench mark for evaluating employee performance thus having a direct relation with the employee performance. Management standards are also associated with the employee engagement as when addressed clearly to the employees, these provide a self-evaluation criterion for the employees thus motivating them to be more engaged towards their work to achieve their personal as well as organizational goals (Mackay et al, 2004).

\subsection{Training}

The success and failure of organizations' employees depends on their performance and it is considered that winning organizations are mostly more concerned about the training and development of their employees knowing that it will aid in employees; knowledge ultimately improving their performance in the organization (Liao and Chang, 2004). Training requirements amplify with the advancement in industry as well as the global markets. Training improves employee performance through developing a sense of teamwork among employees as well as contributing positively towards their knowledge and information about their job (Gruman and Saks, 2011). Trainings providing information about innovation aid more to the employees' knowledge and helps improving employees' performance aligning with the changing requirements of organization, industry and the market. Trainings influence employee performance in a positive manner, thus organizations are more focused about employees' training and development to improve their performance and gain the competitive advantage in the market (Ellinger et al, 2003).

\subsection{Employee Engagement}

Employees' engagement incorporates the willingness of individuals to completely invest their selves into an organizational role. It is found that when employees are contended with their jobs as well as organizations, they are motivated to contribute in the organization at their maximum level. They provide their complete efforts to attain the organizational goals. Such engagement of employees helps them improving their performance in the organization (Saks, 2006).

Organizations are striving for improving their performance as now enhanced efficiency and productivity is required by the organizations to survive in the market. Thus, management is facing challenges to cope with the fierce competition of the market, hence focusing on improving employees' engagement towards their work ultimately improving their performance (Anitha, 2014). According to Sharma and Anupama (2010) employee engagement is driven by the employee satisfaction because employees are not ready to be engaged with their work unless they are satisfied from their jobs. Organizations providing trainings to their employees are also successful in engaging their employees with their work as trainings help them improve their knowledge and skills and being more skilful towards their jobs they are even more engaged towards them (Mehrzi and Singh, 2016).

Management standards are found to be significantly associated with employee engagement as they provide a benchmark for organization to evaluate employees' performance as well as providing such benchmarks for employees for selfassessment. Employees' self-assessment motivates them to be more engaged towards their work so that they can perform up to the mark (Mackay et al, 2004).

\subsection{Employees' Satisfaction and Employee Engagement}

According to Harter et al (2002) employees' when satisfied for their jobs and their organization are found to be more engaged towards their work, thus employee satisfaction leads towards employee engagement. Organizations requiring enhanced performance should focus on satisfying their employees. Employees are satisfied when organizations successfully align their individual goals with the organizational goals, such alignment also attracts them to be more engaged towards their jobs because they are satisfied that organizational goal achievement will ultimately result in their own goal attainment (Mokaya and Kipyegon, 2014).

\subsection{Management Standards and Employee Engagement}

As management standards are the benchmarks and proven frameworks adopted by the organizations to evaluate performance at different levels. Such standards not only provide benchmarks for the management, but also for the employees to evaluate and compare themselves to improve their contribution towards organization (Mackay et al, 2004). Thus, comparing themselves with the management standards employees are motivated to be more engaged towards their work. While employee engagement ultimately leads them towards improved performance. Management standards also highlight the discrepancies and differences between the required and the actual performance thus facilitate employees to know that how much they are required to be further engaged towards their work to attain their individual and organizational goals (Rich et al, 2010).

\subsection{Training and Employee Engagement}

Organizations focus on training and development of their employees as they have realised the significance of employees as an important source generating competitive advantage for the organization. Trainings contribute positively in enhancing 
employees' knowledge of their jobs as well as enhance their skills required for the job (Saks, 2006). When employees get all the required skills and knowledge required for their jobs, they are more confidant performing it, hence enhancing employee engagement (Mehrzi and Singh, 2016).

\subsection{Employees' Engagement and Employee Performance}

More engaged employees are found to be more performing ones as it is found that when employees are engaged towards their jobs they try their best to perform up to their maximum possible levels (Anitha, 2014). Hence employee engagement is among one of the major factors influencing employee performance in the organization. When employees are engaged towards their job, they contribute positively in attaining organizational goals, but it only happens when organizations are successful in attaining employees' satisfaction (Rich et al, 2010). According to Markos and Sridevi (2010) satisfied employees are more engaged towards enhancing their performance and contributing well in organizational goal attainment.

The review of previous studies has highlighted the relationships among variables of current study. The literature review indicates that all factors under study are explored in different previous studies, but their combined impact is not studied yet. Thus, current study not only examines their combined impact as well as their relationships in quite different manner. Thus, the proposed conceptual framework is given below that highlights the proposed relationships among all variables of study.

Figure 1: Conceptual Framework

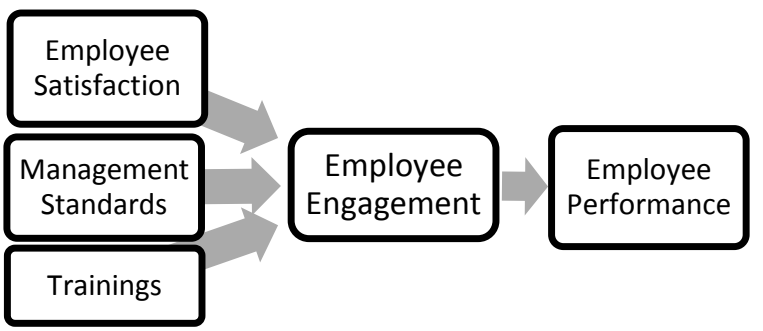

Figure 1 indicates the hypothesised relationship among the variables of study. The conceptual framework indicates that employee satisfaction, management standards and training are the independent variables that influence employee engagement. Employee engagement is the mediating variable of study that being influenced by the independent variables, has an impact on employee performance.

\subsection{Proposed Hypothesis}

Current study tests the following hypothesis:

Ho1: Employee Satisfaction has significant influence on Employee engagement.

Ho2: Management Standards has significant influence on Employee engagement.

Ho3: Training has significant influence on Employee engagement.

Ho4: Employee engagement has significant influence on Employee Performance.

\section{DATA AND METHODOLOGY}

Current study adopts quantitative research method collecting data from administrative managers and executive managers of 50 manufacturing firms from Jordanian industrial sector; delivering 2 questionnaires to each firm where one for the administrative manager and one for the executive manager individually. They were asked different questions about employee satisfaction, management standards, trainings, employee engagement and employee performance. Following questions are asked through questionnaire on a five-point Likert scale indicating 1 for strongly agree to 5 strongly disagree:

1. Employees satisfaction is necessary to get them engaged towards their work.

2. Satisfied employees are more engaged towards their tasks in the organization.

3. Employees' satisfaction engages the employees towards their jobs more keenly, hence resulting in their improved performance.

4. Management standards provide the bench mark to evaluate employee performance.

5. Management standards provide the benchmark for employees for their self-assessment. 
6. Employees when find discrepancies among their performance and management standards, become more engaged towards their jobs.

7. Employee training provide them with the necessary skills and knowledge required for their job performance.

8. Employee training makes them more confident towards their jobs.

9. Employee training enhances employees' interest towards their jobs, thus being more engaged towards it.

10. More engaged employees perform well comparatively.

11. Employee engagement enhances employee performance.

Data collected through this questionnaire is organized in SPSS and then analysed through structural equation modelling in AMOS. Descriptive analysis and structural equation modelling are implemented to find out the results of study.

\section{FINDINGS AND DISCUSSIONS}

The reliability of the measurement scales of study are tested through alpha having minimum acceptable level of 0.7 while alpha values for employee satisfaction, management standards, training, employee engagement and employee performance are $0.86,0.72,0.81,0.79$ and 0.84 respectively, hence indicating the internal consistency of the scales.

Descriptive statistics, tested through SPSS, for demographics indicate the following results:

Table 1: Demographics of Study

\begin{tabular}{|l|c|c|c|c|}
\hline Gender & Male & Female & & \\
\hline Frequency (\%) & $69.6 \%$ & $31.4 \%$ & & \\
\hline Age & $20-30$ & $30-40$ & $40-50$ & $22.5 \%$ \\
\hline Frequency (\%) & $47 \%$ & $30.5 \%$ & $10-15$ & $15+$ \\
\hline Experience & $1-5$ & $5-10$ & $26 \%$ & $17.9 \%$ \\
\hline Frequency (\%) & $21.3 \%$ & $34.8 \%$ & \\
\hline
\end{tabular}

The proposed relationships among variables according to the model of study are analysed through structural equation modelling in AMOS while results are drawn based on different fit indices like GFI, CMIN, NFI, RMSEA and chi-square. The null hypothesis proposed by chi-square indicates that estimated model is good fit, indicating that the proposed relationships of variables of study are true. Chi-square value of estimated model is 0.005 with a p-value of 0.932 , indicating that chi square has insignificant results, hence could not reject the null hypothesis. Thus, the results obtained from chisquare indicate that the proposed relations are good. The results are further validated by other badness and goodness fit indices. Results are drawn on different criteria like for goodness of fit of the model, CMIN should have lower value, GFI and NFI should have values near to 1 . While RMSEA having greater value like near to 1 shows the badness of fit of the estimated model. the results obtained for these indices are as follows:

Table 2: Model Fit Indices

\begin{tabular}{|c|c|c|c|}
\hline CMIN & GFI & NFI & RMSEA \\
\hline 0.004 & 0.92 & 0.93 & 0.000 \\
\hline
\end{tabular}

The results of indices, shown in table 2 illustrate that the estimated model has goodness of fit according to all indices. Hence, the proposed relationships among the independent, dependant and mediating variables are accurate. Following $g$ regression weights are obtained for the estimated model of study: 
Table 3: Regression Weights of Estimated Model

\begin{tabular}{|c|c|c|c|}
\hline & Estimate & S. E & $\mathbf{P}$ \\
\hline Employee Satisfaction ? Employee Engagement & .668 & .053 & $* * *$ \\
\hline Management Standards [ Employee Engagement & .197 & .028 & $* * *$ \\
\hline Training ? Employee Engagement & .568 & .074 & $* * *$ \\
\hline Employee Engagement [ Employee Performance & .178 & .039 & $* * *$ \\
\hline
\end{tabular}

Table 3 illustrates that significant relationships are found among the variables of study. Thus, employee satisfaction, management standards and training have significant positive impact on employee engagement while employee engagement has significant positive impact on employee performance. The obtained results indicate that all the proposed hypothesis of study is supported and can be summarised as follows:

Table 4: Results of Hypothesis

\begin{tabular}{|l|l|}
\hline Hypothesis & Result \\
\hline Ho1: Employee Satisfaction has significant influence on Employee engagement. & Supported \\
\hline Ho2: Management Standards has significant influence on Employee engagement. & Supported \\
\hline Ho3: Training has significant influence on Employee engagement. & Supported \\
\hline Ho4: Employee engagement has significant influence on Employee Performance. & Supported \\
\hline
\end{tabular}

Current study explored the determinants of employee performance. Employee satisfaction, management standards and training are the significant factors influencing the employee performance while having direct impact on employee engagement that ultimately results in enhancing employee performance. The results obtained from empirical testing of data indicate that the variables of study have significant positive relationships among each other. It is found that employee satisfaction has significant positive relationship with employee engagement while employee engagement has significant positive relationship with employee performance. Similarly, management standards and trainings also have significant positive relationship with employee engagement and employee engagement significantly influences employee performance positively. The current study found that employee satisfaction, management standards, and trainings influence employee performance through their engagement towards their work. Thus, employee satisfaction, management standards, trainings and employee engagement are the influencing factors of employee performance. Thus, current study found these four determinants of employee performance.

\section{CONCLUSION}

Fierce competition in business world has forced the organizations to generate and retain any competitive advantage that is vital for their survival in the market. all economies across the world are facing similar situations due to emergence of globalisation and same is the case with Jordan. Thus, to cope with such situations, organizations have realised the value of human resource as one of the important source generating competitive advantage for the organization. Employees are an important asset of the organization as they contribute positively in organizational goal attainment through their performance. Thus, organizations always try to enhance their performance to lead them towards goal attainment. For this purpose, they are required to find out the factors that contribute positively in enhancing employees' performance. Current study explored such factors and found that employee satisfaction, management standards, trainings and employee 
engagement are the determinants of employee performance. Satisfied employees are more engaged towards their jobs thus try to improve their performance and their engagement towards work helps them enhancing their performance. Management standards through providing benchmarks leads towards employee engagement. Similarly, trainings contribute in enhancing skills and knowledge of the employees and being more confidant after trainings they become more engaged towards their jobs, ultimately focusing on enhancing their performance in the organization. The study found that employee satisfaction, management standards and trainings have significant positive impact on employee engagement that ultimately have significant positive impact on employee performance.

Current study significantly contributes to the knowledge and practice of management through highlighting the determinants of employee performance. The study highlights the importance and positive contribution of different factors towards employee performance. Researchers can further validate the impact of these factors in different aspects. While managers can focus on these factors to enhance their employees' performance to attain their organizational goals. The sample size for study is small as only 100 respondents are involved in the study while such study can be conducted on a large sample to obtain more reliable results. Moreover, the model may incorporate few other factors like employee motivation, employee evaluation etc. it may also explore the mediating role of other factors as well as the direct and indirect impacts of factors can be explored that are not investigated by the current research.

\section{REFERENCES}

Anitha, J. 2014, "Determinants of Employee Engagement and their Impact on Employee Performance", International Journal of Productivity and Performance Management, Vol. 63, no. 3, pp. 308-323.

Ellinger, A. D., Ellinger, A. E. and Keller, S. B. 2003, "Supervisory Coaching Behaviour, Employee Satisfaction and Warehouse Employee Performance: A Dyadic Perspective in the Distribution Industry", Human Resource Development Quarterly, Vol. 14, no. 4, pp. 435-458.

Gitongu, M. K., Kingi, W. and Uzel, J. M. M. 2016, “Determinants of Employees' Performance of State Parastatals in Kenya: Kenya Ports Authority", International Journal of Humanities and Social Science, vol. 6, no. 10, pp. 197-204.

Liao, H. and Chang, A. 2004, "A Multilevel Investigation of Factors Influencing Employee Service Performance and Customer Outcomes", Academy of Management Journal, Vol. 47, no. 1, pp. 41-58.

Gruman, J. A. and Saks, A. M. 2011, "Performance Management and Employee Engagement", Human Resource Management Review, Vol. 21, no. 2, pp. 123-136.

Harter, J. K., Schmidt, F. L. and Hayes, T. L. 2002,"Business Unit Level Relationship between Employee Satisfaction, Employee Engagement, and Business Outcomes: A Meta-Analysis", Journal of Applied Psychology, Vol. 87, no. 2, pp. 268279.

Mackay, C. J., Cousins, R., Kelly, P. J., Lee, S. and McCaig, R. H. 2004, "Management Standards and Work-Related Stress in the UK: Policy Background and Science", International Journal of Work, Health and Organizations, Vol. 18, no. 2, pp. 91-112.

Markos, S. and Sridevi, M. S. 2010, "Employee Engagement: The Key to Improving Performance", International Journal of Business and Management, Vol. 5, no. 12, pp. 89-96.

Mehrzi, N. and Singh, S. K. 2016, "Competing through Employee Engagement: A Proposed Framework", International Journal of Productivity and Performance Management, Vol. 65, no. 6, pp. 831-843.

Mokaya, S. O. and Kipyegon, M. J. 2014, "Determinants of Employee Engagement in the Banking Industry in Kenya; Case of Cooperative Bank", Journal of Human Resource Management and Labour Studies, Vol. 2, no. 2, pp. 187-200.

Rich, B. L., Lepine, J. A. and Crawford, E. R. 2010, “Job Engagement: Antecedents and Effects on Job Performance”, Academy of Management Journal, Vol. 53, no. 3, pp. 617-635.

Saks, A. M. 2006, "Antecedents and Consequences of Employee Engagement", Journal of Managerial Psychology, Vol. 21, no. 7, pp. 600-619.

Sharma, B. R., and Anupama, R. 2010, "Determinants of Employee Engagement in a Private Organization: An Exploratory Study" Advances in Management, vol. 3, no. 10. 